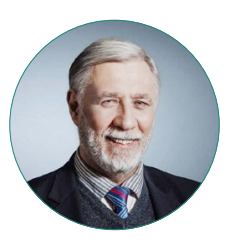
А. В. Шариков

\title{
ГЛОБАЛЬНОЕ ИНФОРМАЦИОННОЕ ОНЛАЙН-ПРОСТРАНСТВО В 2020 Г.: ДИНАМИЧЕСКИЕ ХАРАКТЕРИСТИКИ
}

\section{Правильная ссылка на статью:}

Шариков А. В. Глобальное информационное онлайн-пространство в 2020 г.: динамические характеристики // Мониторинг общественного мнения: экономические и социальные перемены. 2021. № 2. C. 445-463. https://doi.org/10.14515/monitoring.2021.2.1926.

\section{For citation:}

Sharikov A. V. (2021) Global Online Media Landscape 2020: Dynamic Characteristics. Monitoring of Public Opinion: Economic and Social Changes. No. 2. P. 445-463. https://doi.org/10.14515/ monitoring.2021.2.1926. (In Russ.) 
ГЛОБАЛЬНОЕ ИНФОРМАЦИОННОЕ ОНЛАЙН-ПРОСТРАНСТВО В 2020 Г.: ДИНАМИЧЕСКИЕ ХАРАКТЕРИСТИКИ

ШАРИКОВ Александр Вячеславович кандидат педагогических наук, старший научный сотрудник, профессор департамента медиа, Национальный исследовательский университет «Высшая школа экономики", Москва, Россия, Москва, Россия E-MAIL: asharikov@hse.ru https://orcid.org/0000-0001-6035-5960

Аннотация. Статья описывает результаты исследования, цель которого - выявить динамические характеристики глобального информационного онлайнпространства в 2020 г. Данное условное пространство рассматривается в языковых и тематических границах, предоставляемых системой FACTIVA, специализирующейся на мониторинге информации политического, экономического и социального характера с использованием ресурсной базы из более чем 30 тыс. онлайн-источников (крупнейшие мировые СМИ, информационные агентства и др.) на 25 языках, которые, по состоянию на 3 марта 2021 г., репрезентировали 91,7\% контента интернета.

Подтверждена тенденция расширения интернета, проявившаяся также в увеличении количества материалов, составляющих ресурсную базу системы FACTIVA. Обнаружена недельная цикличность производства новых материалов, которая объясняется чередованием будних и выходных дней. Выявлена привязка к традициям различных стран в организации выходных дней в зависимости от преобладания типа культуры (христианской, мусульманской и пр.). В странах христианской традиции минимум новых публикаций наблюдается по воскресень-
GLOBAL ONLINE MEDIA LANDSCAPE 2020: DYNAMIC CHARACTERISTICS

Alexander V. SHARIKOV ${ }^{1}$ - Cand. Sci. (Ped.), Senior Research Fellow, Professor at the School of Media

E-MAIL: asharikov@hse.ru

https://orcid.org/0000-0001-6035-5960

${ }^{1}$ HSE University, Moscow, Russia

Abstract. The article presents a study, which purpose was to identify dynamic characteristics of the global online media landscape in 2020. The media landscape is considered within linguistic and thematic boundaries of FACTIVA - a specialized monitor system for political, economic and social information. FACTIVA's resource base includes more than 30,000 online sources in 25 languages, representing $91.7 \%$ of the Internet's content. As a result of the study, a number of dynamic patterns have been identified. Firstly, an increase in the number of the materials, which FACTIVA operates, confirms the trend for the Internet expansion. Secondly, the production of new materials follows a strict weekly cycle based on the alternation of weekdays and weekends. The latter, in turn, depends on traditions of different countries and the type of culture prevails in them (Christian, Muslim, etc.). Thus, in countries of the Christian tradition, a minimum of new publications is observed on Sundays, in Muslim countries - on Fridays. On a global scale, the peak in the number of published materials falls on Thursday. Thirdly, two new dynamic concepts - "global media splash" and "global media storm" have been introduced into scientific use, as well as a 
ям, в мусульманских странах - по пятницам. Пик количества материалов в глобальном масштабе приходится на четверг. В научный обиход введены два новых динамических концепта, описывающих изменчивость появления онлайн-материалов. Первый - «глобальный медиавсплеск", описывающий существенный рост количества продуцируемых материалов в течение нескольких дней по сравнению с аналогичными днями предыдущей недели. Второй"Глобальный медиашторм", проявляется в сравнении с предыдущим месяцем. Сильными предложено считать глобальные медиавсплески и медиаштормы, при которых количество материалов увеличивается минимум на $15 \%$.

Глобальный медиашторм не всегда связан с краткосрочными сенсационными материалами. Так, глобальный медиавсплеск, переросший в медиашторм, был зафиксирован в связи с убийством иранского генерала Касема Сулеймани и последующими событиями. А мощнейший глобальный медиашторм, при котором сильных глобальных медиавсплесков не наблюдалось, обусловлен пандемией COVID-19.

Ключевые слова: глобальное информационное онлайн-пространство, цикличность глобального информационного онлайн-пространства, глобальный медиавсплеск, глобальный медиашторм, FACTIVA

Благодарность. Работа выполнена на факультете коммуникаций, медиа и дизайна в рамках научно-исследовательского проекта «Трансформация картины мира в глобальном информационном онлайн-пространстве под влиянием пандемии COVID-19". criterion for measuring their strength has been proposed. "Global media splash" describes a significant increase in the number of materials over several days compared to similar days in the previous week. The "global media storm" is manifested in comparison with the previous month. The article proposes to consider global media splashes and media storms as strong when the amount of the media materials increases by at least $15 \%$. The global media storm may not be related to short-term sensational stories. For example, in January 2020, a global media splash which turned into a media storm was recorded in connection with the assassination of Iranian General Qasem Soleimani and subsequent events. The most powerful global media storm in 2020 was caused by the COVID-19 pandemic, but there were no strong global media splashes during this period.

Keywords: global online media landscape, global online media space syclicity, global media splash, global media storm, FACTIVA

Acknowledgments. The work was performed at the Faculty of Communications, Media and Design within the framework of the research project "Transformation of the world picture in the global information online space under the influence of the COVID-19 pandemic". 


\section{Глобальное информационное онлайн-пространство в 2020 г.: динамические характеристики}

Цель настоящей статьи - выявить динамические характеристики глобального информационного онлайн-пространства в 2020 г. и попытаться осмыслить его как единое целое в своем движении. В 2020 г., прошедшем под знаком пандемии COVID-19, эти динамические характеристики проявились особенно ярко. Статья структурирована следующим образом: сначала мы проведем небольшой исторический экскурс - проследим, когда в мире начались первые исследования глобальных информационных процессов и на каких концептуальных основаниях они строились. Затем проанализируем, как развивалось данное направление исследований. Далее мы обратимся к современности и попытаемся осмыслить бытование глобального информационного онлайн-пространства на материале эмпирических данных, полученных в 2020 г. с помощью мониторинга контента ведущих мировых интернет-ресурсов, описав соответствующие динамические характеристики, факты и тенденции.

\section{Краткий исторический экскурс}

Ранние практики и исследования. Изучению глобальных информационных процессов предшествовало начавшееся в 1920-е годы международное радиовещание в коротковолновом диапазоне, с помощью которого радиосигнал может распространяться на тысячи километров. Это привело к созданию в конце 1920-х годов радиостанций, систематически транслирующих информацию на дальние территории в пропагандистских целях. В русскоязычной литературе применительно к такого рода практике сложилось понятие "иновещание", которым стали называть "вещание на аудиторию за пределами страны" [Современная идеологическая..., 1984: 138]. Как указывает А. Ф. Панфилов, первой в мире иновещательной акцией следует считать радиотрансляцию из США на страны Латинской Америки, состоявшуюся 25 мая 1924 г. [Панфилов, 1984: 20]. Вскоре аналогичные эксперименты стали осуществлять и другие страны-Великобритания, Испания, Италия, СССР, Франция и др. В 1939 г. был организован «Принстонский университетский центр по прослушиванию" (Princeton Listening Centre), который считается "пионером в области изучения иностранного коротковолнового радиовещания" [Панфилов, 1984: 39]. Так постепенно сложились предпосылки для исследования мировых информационных процессов.

Концепция свободного потока информации. О необходимости "свободного потока информации" между странами как об инструменте внешней политики заговорили незадолго до начала Второй мировой войны (см., например, [Bernstein, 1935]). А когда она началась, произошло невиданное до того усиление роли иновещания. Радиопропаганда приняла воистину глобальные масштабы, а число языков, на которых она велась ведущими мировыми государствами, уже составляло в каждой стране от десятка и выше. Так, в СССР в 1944 г. иновещание велось на 29 иностранных языках [Кашлев, 1988: 58].

После окончания войны с подачи западных государств концепция, или доктрина, "свободного потока информации" активно обсуждалась на крупных международных площадках. Ее суть состоит в том, что в мире должны быть приняты нормы 
права, обеспечивающие беспрепятственное распространение информации между странами. В несколько иных формулировках данная идея была закреплена в основополагающих международных документах: в Уставе ЮНЕСКО в 1945 г. $^{1}$ и во Всеобщей декларации прав человека ООН в 1948 г. ${ }^{2}$ C 1950 г. ЮНЕСКО на регулярной основе собирает сведения о средствах массовой информации по странам и публикует эти данные ${ }^{3}$.

Либерально-гуманистические идеи ООН, ЮНЕСКО и других ведущих международных организаций декларировались на фоне возникновения и усиления в мире идеологического противостояния, которое проявлялось, как минимум, в двух аспектах, "по двум осям" в терминах того времени: “Запад-Восток" и "Север-Юг”. Ось "Запад - Восток" отражала противостояние идей социализма, носителями которого были СССР и страны социалистического лагеря, и идей капитализма, которые проповедовали ведущие западные страны во главе с США. Данное противостояние в сфере иновещания приняло характер информационной войны, которую также называли "психологической" [Лайнбарджер, 1962].

Идеологическое противостояние по оси "Север - Юг" отражало процессы распада мировой колониальной системы, постепенно переходящей к состоянию, характеризуемому как неоколониализм,- - экономическая зависимость освободившихся стран от бывших метрополий. "Свободный поток информации" на деле оказывался гибким инструментом давления развитых государств на развивающиеся страны. При этом обратный поток от развивающихся к развитым странам оказывался существенно меньшим по объему. Следовательно, в реальности "свободный поток информации" был однонаправленным: от экономически сильных стран к экономически слабым. Эти факты привели к критике концепции “свободного потока информации" и попыткам разработать альтернативные подходы.

Концепция нового мирового информационного и коммуникационного порядка. В рамках ЮНЕСКО ключевым стал подход, известный как "Концепция нового мирового информационного и коммуникационного порядка" ("New World Information and Communication Order", сокращенно NWICO) ${ }^{4}$, акцентировавший необходимость отказа от колониальных и неоколониальных принципов организации распространения информации в мире.

В 1976 г. вышла книга Герберта Шиллера «Коммуникации и культурное господство" (Communication and Cultural Domination) [Шиллер, 1980], имевшая большой резонанс как в академическом мире, так и среди государственных и общественных деятелей. В ней автор убедительно продемонстрировал, как, опираясь на концепцию "свободного потока информации", США и другие страны, по сути, осуществляют политику "информационного империализма" в мире с помощью средств массовой коммуникации. Концепция "свободного потока информации",

\footnotetext{
1 Устав Организации Объединенных наций по вопросам образования, науки и культуры / Комиссия Российской Федерации по делам ЮНЕCKO. URL: http://unesco.ru/wp-content/uploads/add/unesco_constitution_ru.pdf (дата обращения: 12.03.2021).

2 Всеобщая декларация прав человека ООН / Организация Объединенных Наций. URL: https://www.un.org/ru/ documents/decl_conv/declarations/declhr.shtml (дата обращения: 12.03.2021).

${ }^{3}$ См., например, World Communications, Press, Radio, Film, Television (report). Paris: UNESCO, 1951.

4 New World Information and Communication Order (NWICO). URL: https://onlinelibrary.wiley.com/doi/10.1002/ 9781405186407.wbiecn013.pub2 (дата обращения: 22.03.2021).
} 
таким образом, превратилась в идеологическую доктрину, оправдывающую давление богатых стран на бедные.

Дискуссии вокруг несправедливого использования телерадиовещания в мире привели к оживленному обсуждению данной проблемы на площадках ООН и других международных организаций. В результате в рамках ЮНЕСКО в 1977 г. была создана Международная комиссия по изучению проблем коммуникации, куда вошли ведущие эксперты в области СМИ из 15 стран. Ее возглавил Шон Макбрайд, лауреат Нобелевской премии мира (1974 г.). Комиссия организовала беспрецедентное исследование международных информационных потоков, первые результаты которого были представлены в докладе на 20-й Генеральной конференции ЮНЕСКО, проходившей в 1978 г. в Париже. В докладе ставился вопрос о том, что мир «нуждается в свободном, более широком и сбалансированном распространении информации" ${ }^{5}$. В 1980 г. исследование было завершено и опубликовано в книге, озаглавленной "Много голосов — один мир" [Many Voices..., 1980].

Деятельность Комиссии Макбрайда, концепция NWICO и основанная на ней декларация ЮНЕСКО вызвали жесткую реакцию со стороны США и Великобритании. Данные события стали одной из причин, почему обе страны покинули ЮНЕСКО: США - в 1984 г., Великобритания - в 1985 г. Их возвращение состоялось лишь много лет спустя: Великобритания вновь вошла в состав организации в 1997 г., а США - в 2003 г. ${ }^{6}$ Демарш ведущих мировых держав привел к необходимости искать компромисс, который постепенно начал складываться в конце 1980-х годов (об этом см., например, [Mehra, 1986]).

Международный обмен информацией и глобализм. С 1960-х годов стали распространяться идеи глобализма, который в теоретическом плане предстал в виде научных разработок, обобщенно называемых глобалистикой. Появление глобалистики принято связывать с возникновением ряда организаций и объединений футурологической направленности, где обсуждались именно глобальные проблемы человечества. Наиболее известные среди них — "Институт проблем будущего" (1965 г., Вена, Австрия) и особенно “Римский клуб» (1968 г., Рим, Италия). В тот же период (1968 г.) вышла книга М. Маклюэна и К. Фиоре «Война и мир в глобальной деревне" (War and Peace in the Global Village; An Inventory of Some of the Current Spastic Situations That Could Be Eliminated by More Feedforward) [Маклюэн, Фиоре, 2012], где авторы анализируют проблемы глобального распространения информации. С этого момента слово "глобальный" (global) стало все чаще употребляться применительно к информационным процессам, постепенно вытесняя слово "Всемирный" (world wide).

В 70-х годах XX века начинается глобальная эра интернета - ведутся первые эксперименты по установлению международной компьютерной связи на расстоянии. С 1990-х годов, после возникновения подсистемы, называемой «Всемирной паутиной" (World Wide Web), средства массовой информации приступают к актив-

\footnotetext{
${ }^{5}$ Декларация об основных принципах, касающихся вклада средств массовой информации в укрепление мира и международного взаимопонимания, в развитие прав человека и в борьбу против расизма и апартеида и подстрекательства к войне // Организация Объединенных Наций. URL: https://www.un.org/ru/documents/decl_conv/ declarations/st_hr1_141.shtml (дата обращения: 12.03.2021).

${ }^{6}$ США вернулись в ЮНЕСКО //Lenta.ru. 2003. 2 октября. URL: https://lenta.ru/news/2003/10/01/unesco/ (дата обращения: 25.03.2021).
} 
ному освоению онлайн-среды. Интернет постепенно превращается в глобальное информационное пространство. Ученые предпринимают попытки осмыслить новое явление на теоретическом уровне, появляется немало исследований, среди которых особо выделяется фундаментальная работа Мануэля Кастельса «Галактика Интернет" (The Internet Galaxy. Reflections on the Internet, Business, and Society), впервые опубликованная в 2001 г. [Кастельс, 2004].

Теория глобального новостного потока. Под влиянием описанных процессов в исследовательском поле постепенно сложилось направление, известное как "теория глобального новостного потока" (Global News Flow Theory). Его истоки следует искать в описанных выше концепциях и дискуссиях (см., например, [Buchanan, Cantril, Unesco, 1953]). Помимо упомянутой проблематики и концептуальных обсуждений, в рамках данного направления было проведено немало эмпирических исследований, которые позволили выявить три фактора, обусловливающие неравномерную представленность различных стран в картине мира, формируемой в СМИ [Kariel, Rosenvall, 1984; Kim, Barnett, 1996; Segev, 2015; Wu, 2000]. Первый из них - уровень экономического развития. Публикации о странах с высоким уровнем экономического развития появляются чаще. Второй фактор - близость описываемого государства стране, СМИ которой публикуют материалы. При этом имеется в виду близость не только территориальная, но также лингвистическая, экономическая, идеологическая и т. п. Третий фактор - события, привлекающие внимание мировой прессы, среди которых особую роль играют разного рода катастрофы (природные, техногенные), а также социальные, политические, экономические и военные конфликты.

Наконец, еще одно важное направление исследований, касающееся выбранной темы, - медиадинамика (media dynamics) и ее аспект, известный как теория новостной динамики (news dynamics theory), в рамках которой рассматривается понятие "медиашторм" [Boydstun, Hardy, Walgrave, 2014; Hollanders, Vliegenthart, 2008; Lowrence, 1996; Wien, Elmelund-Praesteker, 2009].

Развитие данного направления исследований усилилось после создания в конце 1990-х годов мониторинговых систем, которые работают с большими массивами текстовых публикаций в интернете. Отметим наиболее известные из них:

- проект LexisNexis ${ }^{7}$, основанный в 1977 г., первоначально мониторил традиционные $\mathrm{CMИ}^{8}$, но с середины 90-х годов прошлого века постепенно переориентировался на онлайн-ресурсы;

- в России с 1996 г. действует мониторинговая система "Интегрум" ;

- в 1999 г. компаниями Dow Jones и Reuters была организована мониторинговая система Dow Jones and Reuters Business Interactive, которая вскоре была выкуплена компанией Dow Jones и стала называться Factiva ${ }^{10}$;

- с 2003 г. действует российская мониторинговая система “Медиалогия» ${ }^{11}$.

\footnotetext{
7 Подробнее о LexisNexis cм.: URL: https://www.lexisnexis.ru/ (дата обращения: 22.03.2021).

8 Мониторинг прессы представляет собой давнюю традицию, восходящую к XVIII веку. C 1990-х годов эта традиция связывается преимущественно с интернетом.

9 Подробнее об "Интегрум» см.: https://integrum.ru/monitoring-smi (дата обращения: 22.03.2021).

10 Подробнее о Factiva см.: https://professional.dowjones.com/factiva/ (дата обращения: 22.03.2021).

11 Подробнее о “Медиалогия» см.: https://www.mlg.ru/ (дата обращения: 22.03.2021).
} 
Отмеченные факты дали новый импульс проектам по изучению глобального информационного онлайн-пространства. На основе перечисленных и некоторых других мониторинговых систем проведено немало эмпирических исследований, в фокусе которых находятся именно онлайновые информационные потоки [Быстрицкий, Шариков, 2021; Казун, 2018; Казун, Казун, 2020; Balmas, 2018; Segev, 2016].

\section{Глобальное информационное онлайн-пространство: рабочая модель}

Несмотря на обширную литературу, посвященную интернету, и множество подходов к его изучению, сконструируем собственную рабочую модель, удобную для настоящего проекта. Поскольку речь идет не обо всем интернете, а лишь о некоторой его части, очертим границы, в пределах которых эта модель будет применена. Обобщенно выделяемый нами сегмент должен быть, во-первых, текстовым контентом; во-вторых, тематически ограничиваться проблемами политики, экономики и социума; в-третьих, не представлять собой литературные, развлекательные и академические тексты; в-четвертых, иметь новостную, аналитическую и публицистическую направленность. Условимся называть данный сегмент интернета "глобальное политико-экономическое и социальное текстовое информационное онлайн-пространство". Однако в контексте настоящей статьи для удобства вместо предложенного развернутого названия будем использовать более короткое выражение "глобальное информационное онлайн-пространство". Данное пространство имеет характеристики, из которых мы выделим динамические, то есть те, что описывают процессы, разворачивающиеся во времени в глобальном масштабе.

Мультилингвистическая структура. Глобальное информационное онлайнпространство представляет собой сложное образование, в котором информация представлена на большом количестве языков. Согласно данным W³Techs, по coстоянию на 3 марта 2021 г. в глобальном интернете присутствовала информация на 182 языках. По количеству контента лидирует английский язык (60,6\%). В пятерку наиболее распространенных также входят: русский (8,3\%), турецкий (3,9\%), испанский $(3,8 \%)$ и персидский $(3,3 \%)$ языки. Одиннадцать языков захватывают чуть более $90 \%$ онлайнового контента - помимо пяти перечисленных, это французский $(2,7 \%)$, немецкий $(2,3 \%)$, японский $(2,1 \%)$, вьетнамский $(1,7 \%)$, китайский $(1,4 \%)$ и арабский $(1,1 \%)^{12}$.

Динамические характеристики. Глобальное информационное онлайнпространство отличается высокой подвижностью. На глобальном уровне каждую минуту появляются все новые и новые материалы на разных языках. Некоторые из них хранятся долго, другие могут появиться на короткий срок, а потом их удаляют. То же самое касается не только отдельных единиц контента - материалов, но и целых ресурсов.

Наблюдения за деятельностью прессы, существующей уже сотни лет, показывают, что время от времени издания быстро подхватывают сенсационные сообщения, тиражируют их, либо просто перепечатывая, либо трансформируя тексты, либо переводя информационные материалы в аналитические и публицистические. Еще в XX веке внимание исследователей привлекали вопросы медиадинамики

\footnotetext{
12 Web Technology Surveys. Usage Statistics of Content Languages for Websites. 2021. 3 March. URL: https://w3techs. com/technologies/overview/content_language (дата обращения: 12.03.2021).
} 
[Lowrence, 1996], которые в XXI веке получили новый импульс в связи с развитием упомянутых выше мониторинговых систем. В исследовательском дискурсе возникло понятие "медиашторм" [Boydstun, Hardy, Walgrave, 2014], а в профессиональном журналистском сленге стали использовать слово "медиавсплеск" ${ }^{13}$. Подразумевается, что медиавсплеск, то есть внезапное повышение количества публикаций по некоторой теме, длится недолго, а медиашторм может растянуться на недели или даже на месяцы. Эти понятия обычно используются для описания динамических процессов в пределах одного издания, например “New York Times" [Boydstun, Hardy, Walgrave, 2014]. В настоящем исследовании мы рассмотрим эти два понятия на глобальном уровне, обозначив их, соответственно, словосочетаниями "глобальный медиавсплеск" и "глобальный медиашторм".

Таким образом, рабочая модель нашего исследования предполагает, что его объектом выступает глобальное информационное политико-экономическое и социальное текстовое информационное онлайн-пространство, а предметом - динамические характеристики этого пространства в течение 2020 г.

Эмпирической базой исследования стала мониторинговая система FACTIVA, проект компании Dow Jones ${ }^{14}$, имеющая развернутую источниковую базу, в которую входят свыше 30 тыс. крупнейших мировых интернет-ресурсов (ведущие информационные агентства, газеты, телеканалы, радиостанции, специализированные порталы и др.). Анализируется информация на 25 языках ${ }^{15}$, которые, согласно данным W33Techs, по состоянию на 3 марта 2021 г. в совокупности репрезентируют 91,7\% контента интернета по лингвистическому основанию ${ }^{16}$.

FACTIVA ориентирована на поиск материалов прежде всего экономической, политической и общесоциальной направленности, что соответствует выбранному объекту исследования. Однако не вполне понятно, насколько полно ресурсная база этой мониторинговой системы репрезентирует глобальное политикоэкономическое и социальное текстовое информационное онлайн-пространство по языковому основанию.

Важно сделать одно методическое замечание. При работе с FACTIVA в основном использовался принцип запросов по кодированным единицам поиска. За единицу принимался материал, в котором хотя бы раз упоминалась закодированная категория. FACTIVA подсчитывает количество таких материалов. При этом из поиска были исключены перепечатанные новости и другие дословно повторяющиеся материалы (например, о ценах, о рынках и т. п.).

\footnotetext{
${ }_{13}^{13}$ Воробьева А. «Приключения" Кубка европейских чемпионов в Украине //ЗвездаРу: Футбольные новости. 2018. 16 мая. URL: https://zvezda-fc.ru/32190-priklyucheniya-kubka-evropeyskih-chempionov-v-ukraine.html (дата обращения: 16.04.2021)

${ }^{14}$ Автор выражает глубокую признательность компании Dow Jones за возможность использовать систему FACTIVA и особую благодарность Андрею Сенуку, официальному представителю компании в России, за консультации в процессе подготовки статьи.

15 Перечислим их: английский, арабский, болгарский, венгерский, датский, индонезийский, испанский, итальянский, каталонский, китайский (строго говоря, мониторинговая система FACTIVA использует два китайских письменных языка - традиционный и упрощенный; в процессе анализа данные о двух языках объединялись), корейский, малайский, немецкий, нидерландский, норвежский, польский, португальский, русский, словацкий, турецкий, финский, французский, чешский, шведский, японский.

${ }^{16}$ Web Technology Surveys. Usage Statistics of Content Languages for Websites. 2021. 3 March. URL: https://w3techs. com/technologies/overview/content_language (дата обращения: 03.03.2021).
} 


\section{Динамические особенности}

Условимся различать две группы динамических процессов при описании глобального информационного онлайн-пространства. Одна группа представляет объективную сторону его бытования, которая проявляется в изменении количества онлайн-ресурсов и материалов, размещаемых на них во временной развертке. Другая группа процессов связана с отбором информации, то есть с тем, что называют формированием повестки дня, которое носит субъективный характер. Рассмотрим некоторые моменты, связанные с каждой из них.

Изменение количества материалов на онлайн-ресурсах. Интернет как глобальная информационная система продолжает расширяться. Растет количество вебсайтов, увеличивается охват аудитории. В 2020 г. число пользователей интернета в мире превысило 5 млрд человек ${ }^{17}$, а количество вебсайтов перешло отметку в 1,8 млрд ${ }^{18}$.

Как в таком контексте меняется количество материалов в рамках системы FACTIVA? Ответ на этот вопрос дает рисунок 1, на котором представлена динамика годового количества материалов, составлявших базу для анализа в FACTIVA в 2010-2020 гг. Видно, что от года к году происходило расширение этой базы: от 59,1 млн материалов в 2010 г. до 102,7 млн в 2020 г.

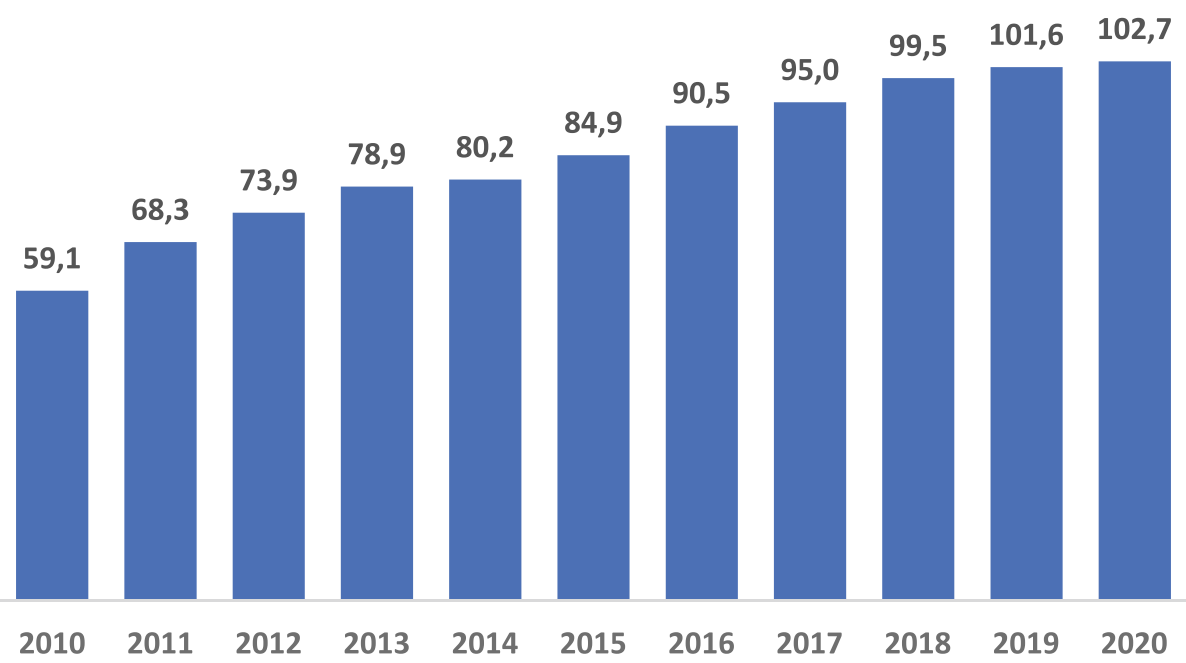

Рис. 1. Динамика годового количества материалов (в млн единиц), составлявших базу для анализа в системе FACTIVA в 2010-2020 гг. на 25 языках

Приведенные данные отражают макропроцессы в годовом измерении. А как ведет себя глобальное информационное онлайн-пространство на уровне ежедневного движения? Редакции всех СМИ и порталов мира работают в ритме жизни общества, в контекст которого они погружены. В каждом обществе есть будние

\footnotetext{
${ }_{17}$ Internet World Stats. URL: https://www.internetworldstats.com/ (дата обращения: 12.03.2021).

${ }^{18}$ Internet Live Stats. URL: https://www.internetlivestats.com/total-number-of-websites/ (дата обращения: 12.03.2021).
} 
и выходные дни. Несмотря на то, что вебсайты открыты круглосуточно в течение всего года, поступление материалов происходит неравномерно. Отсюда гипотеза: количество материалов, выкладываемых на онлайн-ресурсы, предположительно, уменьшается по выходным и увеличивается по будним дням. Для проверки данной гипотезы в рамках системы FACTIVA были выгружены данные по дням. Мы ограничимся здесь рассмотрением результатов за первое полугодие 2020 г. (см. рис. 2).

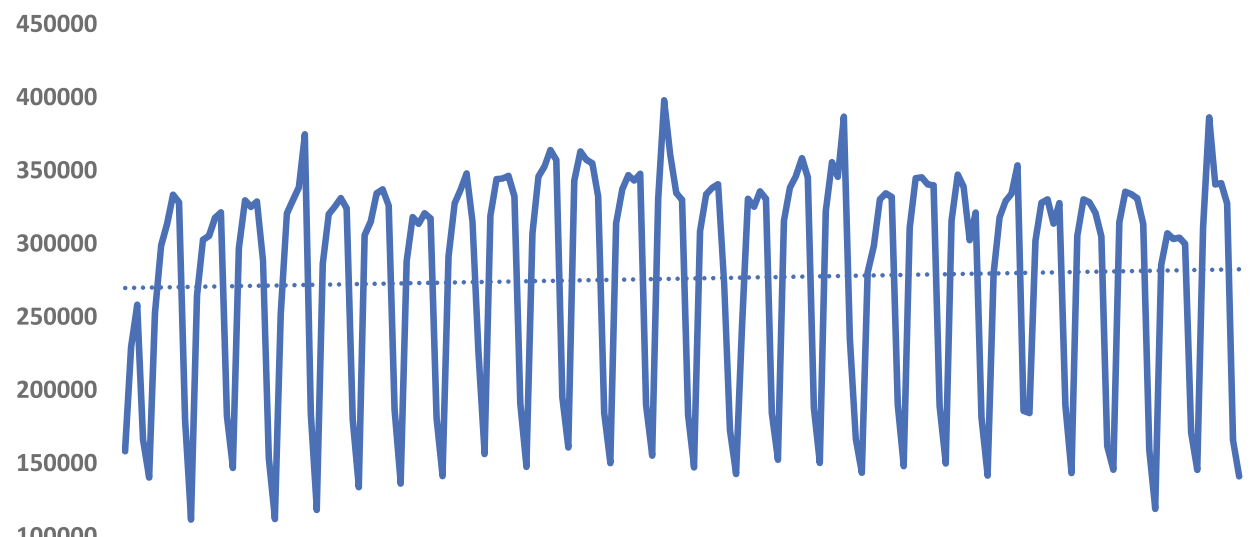

50000

0

01.01.20

01.02 .20

01.03.20

01.04.20

01.05.20

01.06.20

01.07.20

Рис. 2. Динамика ежедневного количества новых материалов на ресурсной базе системы FACTIVA с 1 января по 5 июля 2020 г.

Из рисунка 2 видно, что процесс ежедневного обновления материалов имеет выраженную цикличность, для определения параметров которой был применен спектральный анализ на основе окон Бартлетта ${ }^{19}$. По результатам анализа выделились два уровня периодичности:

1) Первый имеет величину периода, равную семи дням, и связан с недельной цикличностью. Он проявляется в том, что от недели к неделе характер последовательности значений с понедельника по воскресенье повторяется, хотя в течение недели количество новых материалов существенно различается для разных дней (см. рис. 3).

2) Второй период равен трем с половиной дням и привязан к закономерностям, проявляющимся внутри недельного интервала. Так, наибольшее количество новых материалов приходится на четверг, в первом полугодии 2020 г. эта величина в среднем составила 336322 единицы. Наименьшее количество за тот же период приходится на воскресенье (143282). Здесь как бы противостоят два отрезка времени примерно по три с половиной дня: с одной стороны, период со второй

\footnotetext{
${ }^{19}$ Анализ проводился с помощью программного пакета IBM SPSS Statistics 27.
} 
половины понедельника по четверг включительно и, с другой стороны, период с пятницы до середины понедельника.

В этом отношении следует вспомнить, что в связи с культурно-историческими традициями в странах наблюдается различие в выходных днях. В государствах с доминированием христианской культуры обязательный выходной - воскресенье, а с доминированием мусульманской культуры-пятница. В странах, где сильны иудейские традиции, выходным считается суббота. Воскресный минимум свидетельствует о том, что большинство источников, составляющих ресурсную базу системы FACTIVA, привязано к христианской культуре. Анализ динамики появления материалов на арабском языке, то есть на главном языке мусульманской культуры, позволил обнаружить пятничные минимумы. Следовательно, гипотеза подтвердилась.

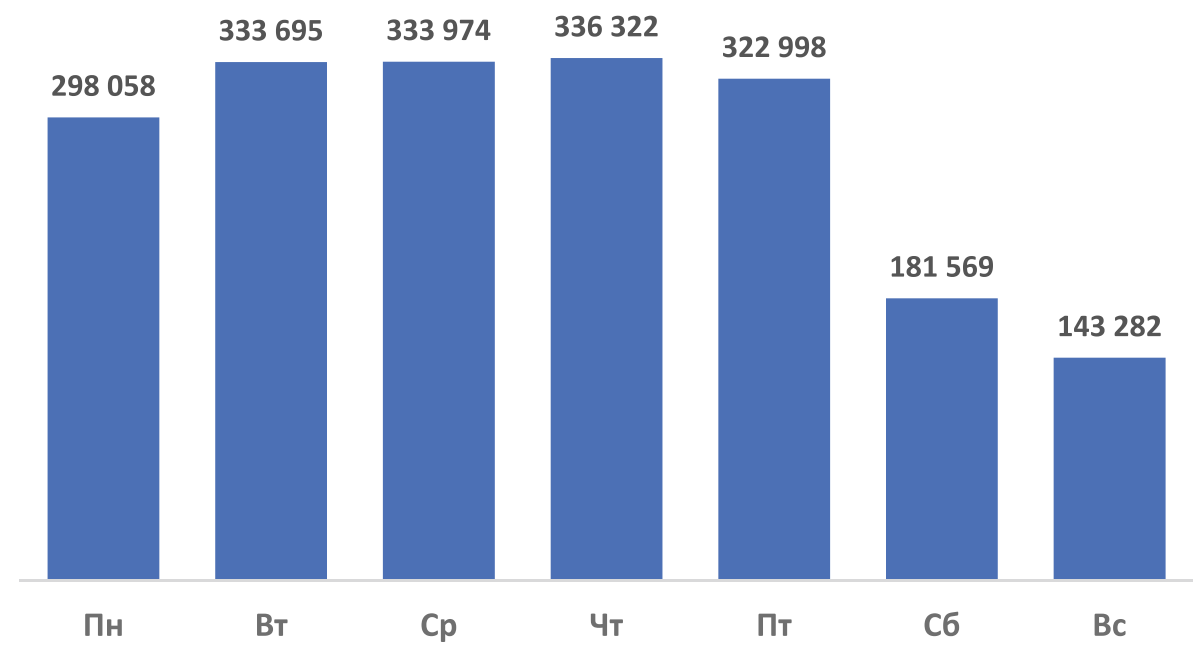

Рис. 3. Среднее количество материалов, составляющих ресурсную основу системы FACTIVA в январе - июле 2020 г. по дням недели

Глобальные медиавсплески и медиаштормы. Обратимся снова к рисунку 2. На фоне ярко проявляющейся циклической регулярности на базе суточных данных отчетливо видны пики количества материалов, наиболее заметный из которых пришелся на 31 марта 2020 г. Этот "Выброс" является примером глобального медиавсплеска. Определим данное понятие.

Условимся называть глобальным медиавсплеском динамический эффект увеличения количества материалов в глобальном информационном онлайн-пространстве в течение суток по сравнению с количеством материалов в аналогичный день предыдущей недели не менее чем на $5 \%$. Будем считать глобальный медиавсплеск сильным, если прирост количества материалов составляет не менее $15 \%$ по сравнению с количеством материалов в аналогичный день предыдущей недели.

На рисунке 2, который дает картину за первое полугодие 2020 г., отчетливо просматриваются четыре глобальных медиавсплеска - 31 января (на $30 \%$ ), 31 марта (на 18\%), 30 апреля (на $8 \%$ ) и 30 июня (на $26 \%$ ). Как видно, не все визуально про- 
являющиеся глобальные медиавсплески на графике реально оказываются сильными. Заметим также, что все они приходятся на последние числа месяца, а два значения - на конец квартала. Объяснение этим глобальным медиавсплескам очень простое: в эти дни публикуется разного рода отчетности, итоги и прогнозы, которые добавляются к имеющемуся массиву информации.

Однако глобальные медиавсплески могут быть не на всем массиве данных, а по определенным темам, географическим объектам, организациям и персонам. Проследим этот процесс на примере материалов об убийстве иранского генерала Касема Сулеймани в пятницу, 3 января 2020 г. (см. рис. 4). Генерал находился в командировке в Ираке и погиб в аэропорту Багдада в ходе ракетного обстрела США. В этот день с пометкой "срочно" все мировые СМИ сообщили о данном событии. Общее число материалов с упоминанием Ирана, выгружаемых системой FACTIVA, составило 10016. Неделей ранее, в пятницу, 27 декабря, Иран упоминался лишь в 1241 публикации, то есть число материалов выросло на 707,1\%, или в восемь с лишним раз. Сильнейший глобальный медиавсплеск! Однако после небольшого снижения в выходные дни на следующей неделе снова начался рост количества публикаций, который достиг пика 8 января, составив 23338 материалов. Это было связано с цепью событий, последовавших за убийством генерала Сулеймани. Среди них атака силами противовоздушной обороны Ирана украинского самолета, который ошибочно был принят за военный объект, нападение бойцов Корпуса стражей иранской революции на американскую военную базу в Ираке и др. Сильнейший глобальный медиавсплеск, приняв характер двойного глобального “медиавзрыва", перешел в настоящий глобальный медиашторм, длившийся более недели.

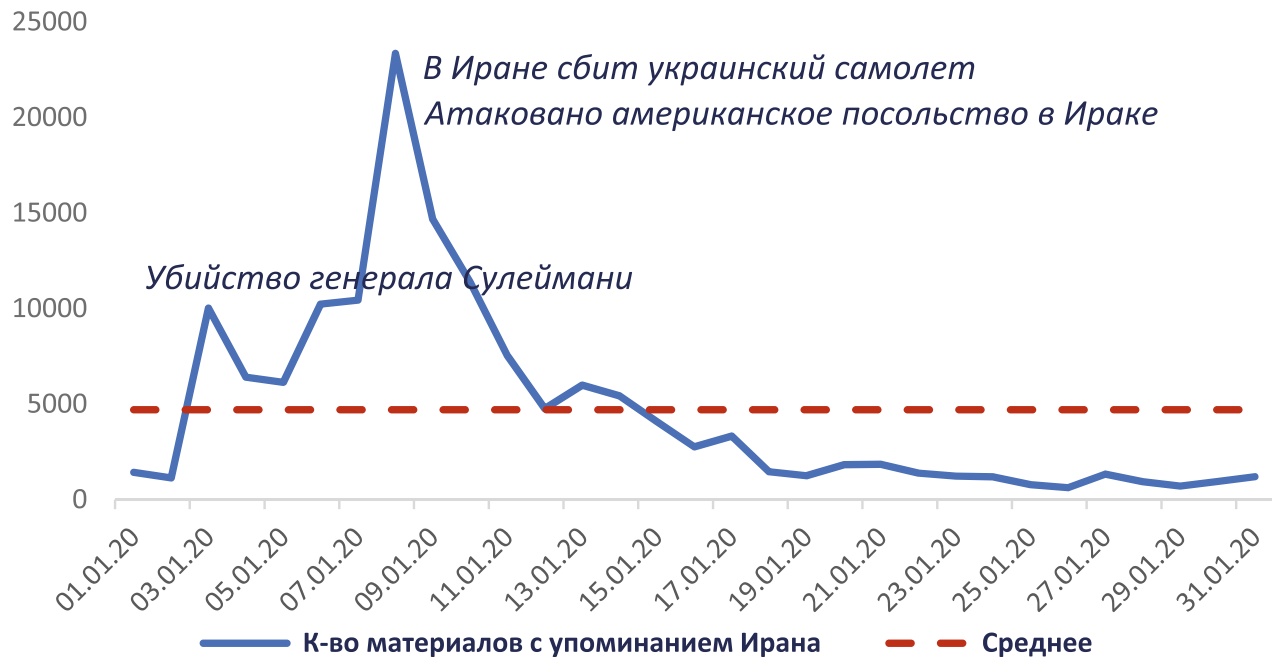

Рис. 4. Количество материалов с упоминанием Ирана по дням в январе 2020 г. совокупно на 25 языках системы FACTIVA

Однако после мощного глобального медиавсплеска вследствие сенсационных событий не всегда возникают глобальные медиаштормы на отрезке одной-двух 
недель. В 2020 г. имелись примеры более длительного глобального медиашторма, который был связан с пандемией COVID-19. Продолжая логику построения определений, условимся называть "глобальным медиаштормом" динамический эффект увеличения количества материалов в глобальном информационном онлайн-пространстве в течение месяца по сравнению с количеством материалов за предыдущий месяц не менее чем на $5 \%$. Будем считать глобальный медиашторм сильным, если прирост количества материалов составляет не менее $15 \%$ по сравнению с предыдущим месяцем.

Опираясь на данное определение, убедимся, что убийство генерала Сулеймани вызвало сильный глобальный медиашторм. В декабре 2019 г. количество материалов с упоминанием Ирана в системе FACTIVA составило 26 727. В январе 2020 г. это число было равно 146046 . Следовательно, прирост составил 446,4\%, что свидетельствует о сильнейшем глобальном медиашторме, что и требовалось доказать.

Рассмотрим рисунок 5, на котором изображена гистограмма, отражающая помесячную динамику появления новых материалов по совокупности всех ресурсов на 25 языках, которыми оперирует FACTIVA, и материалов, объединяющих три стандартные (кодируемые) темы - «новые коронавирусы", "вспышки заболеваний/эпидемии" и "здравоохранение».

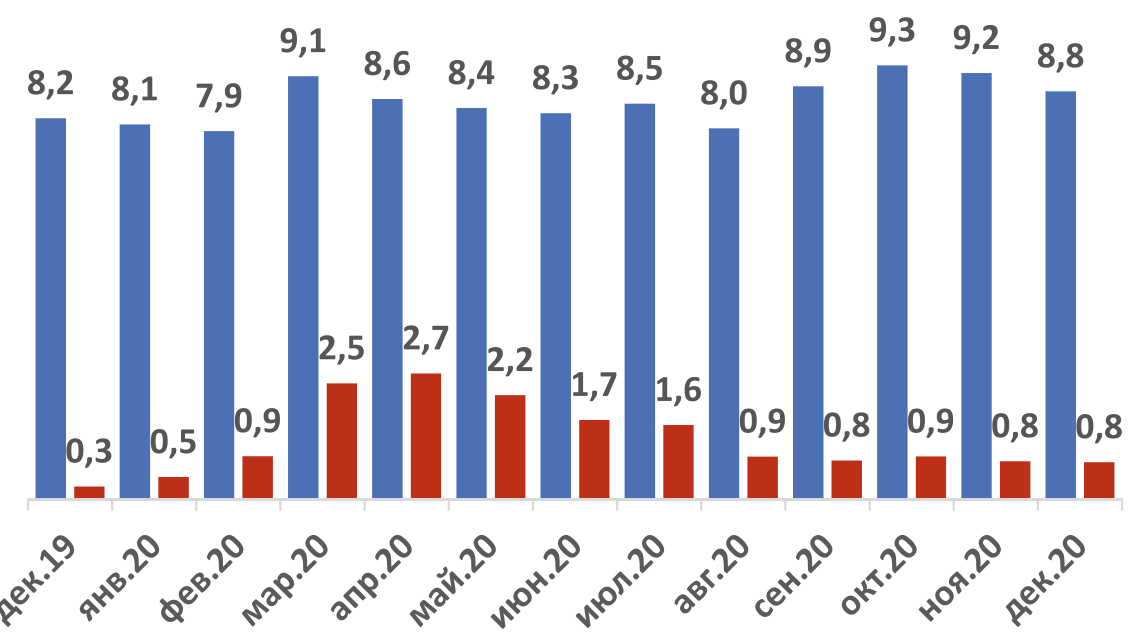

Все материалы в коронавирус, эпидемии, здравоохранение

Рис. 5. Динамика количества материалов, составивших ресурсный базис системы FACTIVA по месяцам с декабря 2019 по декабрь 2020 г., и количество материалов о пандемии COVID-19

На рисунке 5 для динамического ряда, отображающего количество всех материалов, лишь один следует считать сильным глобальным медиаштормом - это переход февраль - март, когда наблюдался рост с 7,9 до 9,1 млн материалов, то есть на $15 \%$. Он отражает развитие процессов пандемии в мире и их освещение 
в глобальном информационном онлайн-пространстве, которые представлены на гистограмме столбиками меньших размеров. На этой тематической последовательности видно, что "ковидное" глобальное медиавозмущение нарастало в течение четырех месяцев - с января по апрель, но наибольший скачок произошел в марте: количество материалов на 25 языках совокупно увеличилось с 0,9 до 2,5 млн, или на 170\%. При этом самый заметный за 2020 г. глобальный медиашторм, по всем материалам наблюдавшийся в феврале и марте, проходил без мощных глобальных медиавсплесков, в логике недельной цикличности, описанной выше, но с постоянным сильным нарастанием от недели к неделе (см. рис. 6).

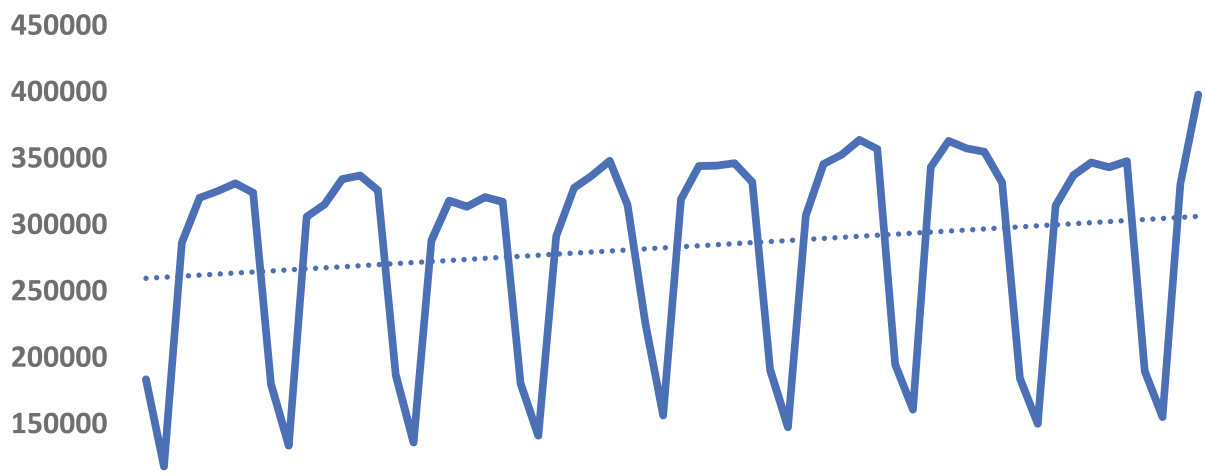

100000

50000

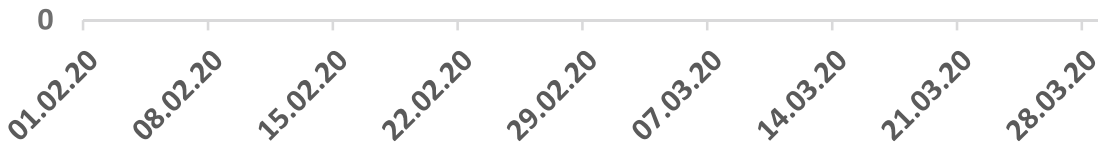

Рис. 6. Динамика ежегодного количества новых материалов на ресурсной базе системы FACTIVA в феврале-марте 2020 г. на 25 языках

Из сказанного следует, что глобальные медиаштормы могут быть как связаны, так и не связаны с сильными глобальными медиавсплесками. Последствия медиавозмущений на отрезках времени длиной в несколько месяцев оказываются весьма существенными. Именно так произошло с освещением эпидемии COVID-19, о которой начали активно писать в январе 2020 г. (см. рис. 5). Сначала она выглядела как локальная вспышка заболевания в Китае, но, начиная с февраля количество материалов по данной теме увеличивалось, что вылилось в относительно медленно нарастающий, но мощный медиашторм глобального масштаба. Если в январе 2020 г. тема COVID-19 была представлена в 0,5 млн материалов (5,9\% всех публикаций), в феврале - 0,9 млн (11,6\%), то в марте уже 2,5 млн или более четверти публикаций $(27,3 \%)$ касались пандемии, а в апреле эта величина достигла своего максимума, составив 2,7 млн (31,4\%), после чего стала снижаться. И хотя осенью 2020 г. началась вторая волна с гораздо более высоким уровнем заболеваемости и смертности, число публикаций, посвящен- 
ных COVID-19, уменьшилось с 0,9 млн (9,8\%) в октябре до 0,8 млн (9,0\%) в декабре 2020 г. Человечество стало испытывать усталость от связанной с пандемией информации.

\section{Заключение}

Мы ввели рабочую модель глобального политико-экономического и социального текстового информационного онлайн-пространства и попытались изучить некоторые ее динамические свойства. Среди всего разнообразия интернет-контента модель отграничивает только текстовые формы информационного (новостного, аналитического, публицистического и т.п.) характера, которые связаны с политикой, экономикой, социумом. Инструментом, с помощью которого изучалось глобальное информационное онлайн-пространство в указанных модельных границах, выступила мониторинговая система FACTIVA, предоставляющая информацию на 25 языках, которые репрезентируют более $90 \%$ контента интернета.

Исследование динамических характеристик модели информационного онлайнпространства привело к следующим результатам:

- Была подтверждена известная тенденция расширения интернета. В рамках системы FACTIVA она проявилась в увеличении количества материалов, составляющих ресурсную базу: за период с 2010 по 2020 г. их количество возросло с 59,1 до 102,7 млн материалов в год.

- Была обнаружена строгая регулярность производства новых материалов, которая сильнее всего просматривается на уровне недельной цикличности, где выявлены две фазы: со второй половины дня понедельника по четверг и с пятницы до середины дня понедельника. Данная периодичность объясняется рабочим циклом, имеющим место в любом обществе. В то же время немаловажную роль играет привязка той или иной страны и языковой зоны к традициям организации выходных дней. Пятница, суббота и воскресенье - это традиционные выходные дни в мусульманской, иудейской и христианской культурах соответственно. В целом в ресурсной базе системы FACTIVA доминирует христианская традиция, поэтому минимум поступления новых публикаций наблюдается в воскресенье, тогда как в мусульманских странах - по пятницам. В первой половине дня понедельника материалы обычно только нарабатываются, если нет каких-то ярких событий, привлекающих прессу. Со второй половины дня понедельника процесс производства текстов набирает привычную скорость. Пик количества публикаций в среднем приходится на четверг.

- В исследовании были отработаны концепты глобального медиавсплеска и глобального медиашторма, то есть существенного роста количества продуцируемых материалов в глобальном информационном онлайн-пространстве либо на сравнительно коротком отрезке времени (глобальный медивсплеск проходит в течение нескольких дней), либо на месячных интервалах (глобальный медиашторм). Были обозначены параметрические границы, позволяющие оценить уровень глобальных медиавсплесков и глобальных медиаштормов. В частности, предложено считать сильными глобальные медиавсплески и глобальные медиаштормы, при которых прирост количества материалов составляет не менее $15 \%$. В 2020 г. самый сильный глобальный медиавсплеск, переросший в глобальный 
медиашторм, наблюдался в январе в связи с убийством иранского генерала Касема Сулеймани, после чего произошло несколько других событий вокруг Ирана, о которых активно писала мировая пресса. В то же время не всегда глобальный медиашторм связан с краткосрочными сенсационными материалами. Мощнейший глобальный медиашторм 2020 г. был обусловлен пандемией COVID-19, когда на протяжении нескольких месяцев в мире наблюдалось нарастание количества материалов, посвященных различным аспектам эпидемии и ее последствиям.

\section{Список литературы (References)}

Быстрицкий А. Г., Шариков А. В. О представленности России в глобальном информационном онлайн-пространстве // Международная жизнь. 2021. № 2. С. 76-93. URL: https://interaffairs.ru/jauthor/material/2469 (дата обращения: 05.04.2021) Bystritskii A. G., Sharikov A. V. On the Representation of Russia in the Global Information Online Space. International Affairs. No. 2. P. 76-93. URL: https://interaffairs.ru/jauthor/material/2469 (accessed: 05.04.2021). (In Russ.)

Казун А. Д. Глобальный новостной поток. О каких странах говорят российские СМИ и почему? //Полития. 2018. № 4. С. 90-105. https://doi.org/10.30570/20785089-2018-91-4-90-105.

Kazun A. D. (2018) Global News Flow (What Countries Russian Media Talk about and Why). Politeia. No. 4. P. 90-105. https://doi.org/10.30570/2078-5089-2018-914-90-105. (In Russ.)

Казун А. П., Казун А.Д. Качество институтов и борьба лидеров стран Большой двадцатки за международную повестку дня // Журнал институциональных исследований. 2020. Т. 12. № 1. С. 128-143. https://doi.org/10.17835/20766297.2020.12.1.128-143.

Kazun A. P., Kazun A. D. (2020) Institutional Quality and the Fight of the G20 Leaders for the International Agenda in Print Media. Journal of Institutional Studies. No. 1. P. 128-143. https://doi.org/10.17835/2076-6297.2020.12.1.128-143. (In Russ.)

Кастельс М. Галактика Интернет: размышление об Интернете, бизнесе и обществе. Екатеринбург:У-Фактория, 2004.

Castells M. (2004) The Internet Galaxy. Reflections on the Internet, Business, and Society. Ekaterinburg: U-Faktoriia. (In Russ.)

Кашлев Ю. Б. Информационный взрыв: международный аспект. М. : Международные отношения, 1988.

Kashlev IU.B. (1988) Information Explosion: International Aspect. Moscow: International Relations. (In Russ.)

Лайнбарджер П. Психологическая война. М.: Воениздат, 1962.

Linebarger P. M. A. (1962) Psychological Warfare. Moscow: Voenizdat. (In Russ.)

Маклюэн М., Фиоре К. Война и мир в глобальной деревне. М. : Астрель, 2012. 
McLuhan M., Fiore Q. (2012) War and Peace in the Global Village; An Inventory of Some of the Current Spastic Situations That Could Be Eliminated by More Feedforward. Moscow: Astrel. (In Russ.)

Панфилов А. Ф. Радиовойна: история и современность. Очерки о внешнеполитической радиопропаганде фашистской Германии, Англии, США и ФРГ. М. : Искусство, 1984.

Panfilov A. F. (1984) Radio War: History and Modernity. Essays on Foreign Policy Radio Propaganda of Fascist Germany, England, the USA and the FRG. Moscow: Iskusstvo. (In Russ.)

Современная идеологическая борьба и проблемы языка / отв. ред. Дешериев Ю.Д. М.: Наука, 1984.

Desheriev Yu.D. (ed.) (1984) Modern Ideological Struggle and Language Problems. Moscow: Nauka. (In Russ.)

Шиллер Г. Манипуляторы сознанием. М. : Мысль, 1980.

Schiller H. I. (1980) Communication and Cultural Domination. Moscow: Mysl. (In Russ.)

Balmas M. (2018) Tell Me Who Is Your Leader, and I Will Tell You Who You Are: Foreign Leaders' Perceived Personality and Public Attitudes Toward Their Countries and Citizenry. American Journal of Political Science. Vol. 62. No. 2. P. 499-514. https:// doi.org/10.1111/ajps.12354.

Bernstein H. (1935) Can We Abolish War? New York, NY: Broadview.

Boydstun A. E., Hardy A., Walgrave S. (2014) Two Faces of Media Attention: Media Storm versus Non-Storm Coverage. Political Communication. Vol. 31. No. 4. P. 509-531.

Buchanan W., Cantril H., Unesco. (1953) How Nations See Each Other: A Study in Public Opinion. Urbana, IL: University of Illinois Press.

Hollanders D., Vliegenthart R. (2008) Telling What Yesterday's News Might be T omorrow: Modeling Media Dynamics. Communications: European Journal of Communication Research. Vol. 33. No. 1. P. 47-68.

Kariel H. G., Rosenvall L. A. (1984) Factors Influencing International News Flow. Journalism and Mass Communication Quarterly. Vol. 61. No. 3. P. 509-666. https:// doi.org/10.1177/107769908406100305.

Kim K., Barnett G. A. (1996) The Determinants of International News Flow a Network Analysis. Communication Research. Vol. 23. No. 3. P. 323-352. https://doi.org/ 10.1177/009365096023003004.

Lowrence R. G. (1996) Accidents, Icons, and Indexing. The Dynamics of News Coverage of Police Use of Force. Political Communication. Vol. 13. P. 437-454.

Many Voices, One World: Communication and Society, Today and Tomorrow: Towards a New More Just and More Efficient World Information and Communication Order. (1980) London: Kogan Page; New York, NY: Unipub; Paris: Unesco. 
Mehra A. (1986) Free Flow of Information: A New Paradigm. New York, NY: Greenwood Press.

Segev E. (2016) International News Flow Online: Global Views With Local Perspectives. New York, NY: Peter Lang.

Segev E. (2015) Visible and Invisible Countries: News Flow Theory Revised. Journalism: Theory, Practice and Criticism. Vol. 16. No. 3. P. 412-428. https://doi.org/10.1177/ 1464884914521579.

Wien C., Elmelund -Praesteker C. (2009) An Anatomy of Media Hypes: Developing a Model for the Dynamics and Structure of Intense Media Coverage of Single Issue. European Journal of Communication. Vol. 24. No. 2. P. 183-201.

Wu H. D. (2000) Systemic Determinants of International News Coverage: A Comparison of 38 Countries. Journal of Communication. 2000. Vol. 50. No. 2. P. 110-130. https:// doi.org/10.1111/j.1460-2466.2000.tb02844.x. 